\title{
Development and characterization of CD22-targeted pegylated-liposomal doxorubicin (IL-PLD)
}

\author{
Robert T. O'Donnell • Shiloh M. Martin • \\ Yunpeng Ma • William C. Zamboni • Joseph M. Tuscano
}

Received: 16 February 2009 / Accepted: 10 March 2009/Published online: 24 March 2009

(C) The Author(s) 2009. This article is published with open access at Springerlink.com

Summary Non-Hodgkin's lymphoma (NHL) is the sixth most common cause of cancer deaths in the U.S. Most NHLs initially respond well to chemotherapy, but relapse is common and treatment is often limited due to the toxicity of chemotherapeutic agents. Pegylated-liposomal doxorubicin (PLD, Ben Venue Laboratories, Inc), a produces less myelotoxicity than non-liposomal (NL) doxorubicin. To further enhance efficacy and NHL targeting and to decrease toxicity, we conjugated an anti-CD22 monoclonal antibody (HB22.7) to the surface of PLD, thereby creating CD22targeted immunoliposomal PLD (IL-PLD). HB22.7 was successfully conjugated to PLD and the resulting IL-PLD exhibits specific binding to CD22-expressing cells as assessed by immunofluorescence staining. IL-PLD exhibits more cytotoxicity than PLD in CD22 positive cell lines but does not increase killing of $\mathrm{CD} 22$ negative cells. The $\mathrm{IC}_{50}$ of

\footnotetext{
R. T. O’Donnell · S. M. Martin · Y. Ma · J. M. Tuscano

Division of Hematology and Oncology, Department of Internal

Medicine, Davis Cancer Center, University of California,

Sacramento, CA, USA
}

R. T. O’Donnell • J. M. Tuscano

Northern California Veterans Administration Healthcare System,

Mather, CA, USA

\section{W. C. Zamboni}

Division of Pharmacotherapy and Experimental Therapeutics, UNC Eshelman School of Pharmacy,

University of North Carolina,

Chapel Hill, NC, USA

W. C. Zamboni

Molecular Therapeutics Program, UNC Lineberger

Comprehensive Cancer Center, University of North Carolina,

Chapel Hill, NC, USA
IL-PLD is 3.1 to 5.4 times lower than that of PLD in CD22+ cell lines while the $\mathrm{IC}_{50}$ of IL-PLD is equal to that of PLD in CD22- cells. Furthermore, IL-PLD remained bound to the CD22+ cells after washing and continued to exert cytotoxic effects, while PLD and NL- doxorubicin could easily be washed from these cells.

Keywords HB22.7 · CD22 · Non-Hodgkin's lymphoma · Liposomes · Doxorubicin

$\begin{array}{ll}\text { Abbreviations } \\ \text { NHL } & \text { non-Hodgkin’s lymphoma } \\ \text { IL-PLD } & \begin{array}{l}\text { immunoliposomal doxorubicin (HB22.7 } \\ \text { conjugated liposomal doxorubicin) }\end{array} \\ \text { PLD } & \begin{array}{l}\text { liposomal doxorubicin } \\ \text { DXR }\end{array}\end{array}$

W. C. Zamboni

UNC Institute for Pharmacogenomics and Individualized Therapy, University of North Carolina,

Chapel Hill, NC, USA

W. C. Zamboni

Carolina Center of Cancer Nanotechnology Excellence,

University of North Carolina,

Chapel Hill, NC, USA

J. M. Tuscano $(\square)$

UC Davis Cancer Center, Division of Hematology and Oncology,

4501 X Street, Suite 3016,

Sacramento, CA 95817, USA

e-mail: joseph.tuscano@ucdmc.ucdavis.edu 


\section{Introduction}

NHL are a heterogeneous group of lymphoid malignancies, $80-90 \%$ of which are of B-cell origin [1]. NHL is the sixth most common cause of cancer-related deaths in the US, with incidence rates almost doubling since the 1970s [2]. Most NHL are initially responsive to chemotherapy, but relapse is common. Furthermore, the efficacy of chemotherapy is limited by toxicity [1].

One of the most important drugs used in NHL therapy is doxorubicin (DXR). DXR is an anthracycline antibiotic that intercalates into DNA in rapidly dividing cells, thereby inhibiting nucleic acid synthesis [3]. Dose-limiting toxicities of DXR include cardiomyopathy [4] and myelosuppression $[5,6]$. Other toxicities include alopecia, hyperpigmentation of nail beds and dermal folds, nausea, vomiting, and stomatitis [5]. Pegylated-liposomal formulations (PLD) of DXR (such as Doxil) have prolonged and higher exposures in plasma and tumor, increased antitumor activity in preclinical models, and reduced toxicity $[7,8]$ compared with non-liposomal (NL) DXR. The increased DXR accumulation in tumors and the decrease in toxicity is thought to be due to the ability of liposomes to extravasate through fenestrated tumor vessels, while in normal tissues, liposomes tend to be confined in the intravascular space since normal vessels are less fenestrated than tumor vessels $[9,10]$. However, toxicity of PLD depends on the lipid formulation, with both fast and slow DXR release from liposomes being least toxic, while intermediate rates of DXR release have varying toxicities [11]. The use of monoclonal antibodies (mAb) conjugated to liposomal drugs (so called immunoliposomes) can further reduce toxicity and increase efficacy by targeting the liposomal drug to the tumor. PLD has been targeted to tumors using anti-CD19 mAbs with success $[11,12]$.

CD22 is a B-lymphocyte-specific glycoprotein expressed by nearly all mature B-lymphocytes but disappears upon terminal maturation to plasma cells. The two amino-terminal immunoglobulin (Ig) domains of CD22 mediate cell adhesion with sialic-acid bearing ligands. Besides its function as a cell adhesion molecule, CD22 also modulates signal transduction through the B-cell receptor and upon ligation, CD22 becomes internalized [13-15]. Anti-CD22 $\mathrm{mAb}$ such as HB22.7, which bind the two amino-terminal Ig domains and specifically block the interaction of CD22 with its ligand, are effective at inducing proliferative responses in primary B-cells and apoptotic responses in neoplastic B-cells [16]. By contrast, anti-CD22 mAbs that do not block ligand binding have only modest functional effects [16, 17]. As most NHL express CD22, it is a promising target for immunotherapy. Targeting CD22 not only allows for specificity, but also may facilitate intracellular drug delivery based on CD22-mediated internalization.
We previously reported the lymphomacidal properties of HB22.7 in nude mice bearing Raji (human B-cell NHL) xenografts [16]. In this study, HB22.7 was conjugated to PLD and tumor cell targeting, cell accumulation of DXR, and cytotoxicity were assessed in vitro. The inclusion of HB22.7 into the immunoliposome was done to specifically target IL-PLD to the NHL, allowing more localized DXR release and less systemic toxicity.

\section{Materials and methods}

\section{Materials}

Sephadex G-50, Sepharose CL-4B, 4-(2-hydroxyethyl)-1piperazine ethanesulphonic acid (HEPES), reduced Triton X-100 and 2-iminothiolane (Traut's reagent) were purchased from Sigma Chemical Co. (St. Louis, MO). PLD, stericly stabilized liposomes containing entrapped doxorubicin, was manufactured by Ben Venue Laboratories, Inc. (Bedford, $\mathrm{OH})$. Goat anti-mouse immunoglobulins fluorescein conjugate (goat anti-mouse Ig-FITC) was purchased from Biosource (Camarillo, CA). BCA ${ }^{\mathrm{TM}}$ protein assay kit and Silver SNAP II Stain Kit were purchased from Pierce (Rockford, IL). RPMI 1640 medium, penicillin-streptomycin and fetal bovine serum (FBS) were purchased from Life Technologies (Carlsbad, CA). The anti-CD22 mAb, HB22.7, was purified from ascites and has been previously characterized [15]. All chemicals were of analytical grade purity.

\section{Cell lines}

The human Burkitt's B-cell lymphoma lines, Raji (ATCC CCL-86), Ramos (ATCC CRL-1596) and the T-cell leukemia cell line, Jurkat (ATCC TIB-152) were obtained from American Type Culture Collection (Rockville, MD). The cells were grown in suspension in full RPMI (supplemented with 10\% fetal bovine serum (FBS), 50 units $/ \mathrm{ml}$ penicillin $\mathrm{G}$, and $50 \mu \mathrm{g} / \mathrm{ml}$ streptomycin sulfate). The cells were maintained in tissue culture flasks at $37^{\circ} \mathrm{C}$ in $5 \% \mathrm{CO} 2$ and $90 \%$ humidity.

Preparation of anti-CD22 MAb (HB22.7)-targeted IL by the post-insertional method

PLD (Doxil ${ }^{\circledR}$ ), a pegylated-liposomal formulation of DXR was prepared and characterized at ALZA Corp. as described previously [18]. The anti-CD22 mAb, HB22.7, was conjugated to PLD using a previously described postinsertional method for transfer of ligands to pre-formed liposomes [19]. Briefly, mAb-coupled micelles were prepared as follows. Mal-PEG-DSPE and mPEG-DSPE were mixed at a 4:1 molar ratio and dried under nitrogen gas until 
no liquid remained. The lipid mixture was further dried in a speed vacuum for an additional $4 \mathrm{~h}$. The dried lipid films were hydrated immediately before $\mathrm{mAb}$ coupling to a concentration of $10 \mathrm{mmol} / \mathrm{L}$ in deoxygenated $25 \mathrm{mmol} / \mathrm{L}$ HEPES ( $\mathrm{pH} 7.4$ ) by heating in a $65^{\circ} \mathrm{C}$ water bath. MAb HB22.7 $(10 \mathrm{mg} / \mathrm{ml})$ was incubated with 2-iminothiolane in HEPES-buffered saline $(\mathrm{pH} \mathrm{8.0)}$ at a molar ratio of 10:1 for $1 \mathrm{~h}$ at room temperature to thiolate the mAb's amino groups. The thiolated $\mathrm{mAb}$ was then chromatographed over a Sephadex G-50 column equilibrated with HEPES-buffered saline $(\mathrm{pH}$ 7.4) and immediately incubated with hydrated micelles overnight under nitrogen gas with continuous stirring. After mAb coupling to micelles, the micelles were incubated with pre-formed liposomes (PLD) at a molar ratio of $0.05: 1$ for $1 \mathrm{~h}$ at $60^{\circ} \mathrm{C}$. The micelle/PLD mixture was then chromatographed over a Sepharose CL-4B column equilibrated in pyrogen-free HEPES-buffered saline ( $\mathrm{pH} 7.4)$ to separate the immunoliposomes (IL-PLD) from PEG-micelles and free $\mathrm{mAb}$. The amount of mAb conjugated to the liposomes was quantified by the $\mathrm{BCA}^{\mathrm{TM}}$ protein assay kit and the coupling ratio ( $\mu \mathrm{g} \mathrm{IgG} / \mu \mathrm{mol}$ liposome phospholipid) was calculated. Phospholipid concentration was determined by the Fiske and Subbarow method [20]. The concentration of the liposomeentrapped DXR was determined by spectrophotometry $(\lambda=$ $490 \mathrm{~nm}$ ) and the size of resulting IL-PLD was determined by dynamic light scattering using a Beckman Coulter N4 MD sub-micron particle analyzer (Fullerton, CA).

\section{In-vitro cytotoxicity assays}

Raji (CD22+), Ramos (CD22+), or Jurkat (CD22-) cells $\left(5 \times 10^{4}\right)$ were plated in 96 well, round bottom plates in a volume of $100 \mu \mathrm{l}$. NL-DXR, PLD and IL-PLD were serially diluted 1:2 with medium to achieve final concentrations of $001-5.0 \mathrm{ug} / \mathrm{ml}$. All samples were plated in triplicate. The plates were incubated at $37^{\circ} \mathrm{C}, 5 \% \mathrm{CO}_{2}$ and $90 \%$ humidity for $1 \mathrm{~h}$, centrifuged, and the cells washed with PBS three times. Following the final wash, cells were re-suspended in $200 \mu \mathrm{l}$ of full RPMI1640 medium and returned to the incubator for $71 \mathrm{~h}$. In some cytotoxicity assays, the cells were treated with the drugs continuously (no washing) for $72 \mathrm{~h}$. A trypan blue exclusion assay was used to measure viability. The dose response logistic equation was applied to the data, and the $\mathrm{IC}_{50}$ was read from the curve.

Immunofluorescence imaging

Raji (CD22+), Ramos (CD22+), or Jurkat (CD22-) cells $\left(1 \times 10^{6}\right)$ were incubated with IL-PLD/ml $(5 \mu \mathrm{g})$ for $1 \mathrm{~h}$ on ice. The cells were washed three times with cold PBS, $\mathrm{pH} 7.4$, to remove unbound IL-PLD and incubated with FITC-labeled goat anti-mouse Ig for $1 \mathrm{~h}$ on ice. Cells were again washed three times with PBS, then fixed with $2 \%$ paraformaldehyde. Images were then acquired (Olympus Motorized Reflected Fluorescence System BX61).

\section{IL-PLD accumulation in CD22 expressing NHL cells}

Raji cells $(\mathrm{CD} 22+)$ were plated in six well plates at $2 \times 10^{6}$ cells/well. Cells were treated with IL-PLD or PLD at final concentrations of $0,0.5 \mu \mathrm{g} / \mathrm{ml}, 1 \mu \mathrm{g} / \mathrm{ml}, 2 \mu \mathrm{g} / \mathrm{ml}, 4 \mu \mathrm{g} / \mathrm{ml}$ and $8 \mu \mathrm{g} / \mathrm{ml}$ for $2 \mathrm{~h}$ at $37^{\circ} \mathrm{C}$. The cells were washed three times with cold PBS. DXR was then extracted by acidified isopropanol ( $75 \mathrm{mM}$ hydrochloric acid in $90 \%$ isopropanol) for $20 \mathrm{~h}$ at $4^{\circ} \mathrm{C}$. DXR concentration extracted from the cells was assayed by microflourometer, using $470 \mathrm{~nm}$ as the excitation and $590 \mathrm{~nm}$ as the emission wavelength.

\section{SDS-PAGE}

HB22.7, PLD, and IL-PLD were run on a $10 \%$ polyacrylamide gel, followed by silver staining with the Pierce SilverSNAP Stain Kit II according to manufacturer's instructions.

DXR in vitro release assay (DXR leakage assay)

PLD and IL-PLD were freshly prepared and NL-DXR, if any, was separated from the liposomal suspensions by elution over a Sepharose CL-4B column. PLD and IL-PLD were then dialyzed for $24 \mathrm{~h}, 48 \mathrm{~h}, 72 \mathrm{~h}$, or $96 \mathrm{~h}$ against PBS $\mathrm{pH} 7.4$ at $37^{\circ} \mathrm{C}$. The percentage release of DXR was analyzed by fluorescence de-quenching measured using $485 \mathrm{~nm}$ as the excitation wavelength and $590 \mathrm{~nm}$ as the emission wavelength. Complete release (100\% de-quenching) of DXR was obtained by lysing PLD or IL-PLD in $50 \mu \mathrm{l}$ of $10 \%(\mathrm{v} / \mathrm{v})$ reduced Triton X-100 in PBS per mL of liposome suspension.

\section{Results}

\section{Characterization of IL-PLD}

The anti-CD22 mAb, HB22.7, was conjugated to PLD as described above. IL-PLD was analyzed via SDS-PAGE to confirm that HB22.7 was incorporated into PLD as shown in Fig. 1a. PLD or IL-PLD were then dialyzed against PBS for $24,48,72$, and $96 \mathrm{~h}$ and the amount of DXR in the dialysate quantified to determine DXR leakage from the liposomes (Fig. 1b). No difference was seen in the amount of DXR leakage from PLD and IL-PLD. For example, IL-PLD and PLD at $96 \mathrm{~h}$ of dialysis displayed $8.6 \%$ versus $7.5 \%$ DXR leakage, respectively (Fig. 1b). The mean \pm SD diameters of PLD and IL-PLD were determined to be $118 \pm \mathrm{nm}$ and $165 \pm$ nm respectively (Fig. 1c). The mean diameters of 

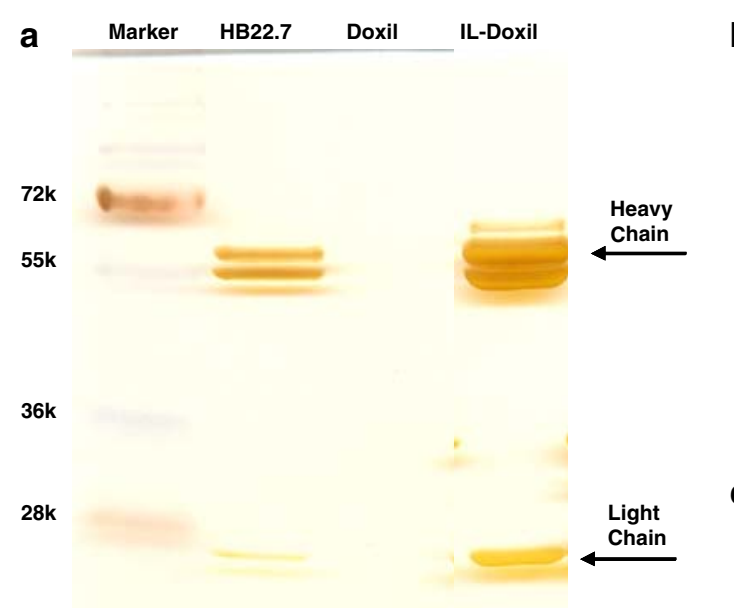

$17 k$

Fig. 1 Post-insertional method for preparation of immunoliposomes. a SDSzPAGE analysis of free mAb (HB22.7), PLD, and IL-PLD. Arrows indicate expected sizes of mAb heavy and light chains. b

PLD and IL-PLD were reduced by $25 \%$ and $26 \%$, respectively, when size was measured in PBS containing $50 \%$ FBS (Fig. 1c).

\section{IL-PLD targets CD22 expressing NHL cell lines}

After determining that HB22.7 was incorporated into PLD, thereby creating IL-PLD (Fig. 1a), it was important to determine that IL-PLD was indeed able to bind CD22 expressing cells. Binding was assessed by fluorescence microscopy using a goat anti-mouse IgG-FITC against the HB22.7 mAb component of IL-PLD. IL-PLD binds to two different B-cell (CD22+) Burkitt's lymphoma cell lines, Raji and Ramos, but did not bind to the Jurkat T-cell leukemia (CD22-) cell line, (Fig. 2).

NHL cell line treated with IL-PLD exhibit increased DXR accumulation compared to PLD treatment

After determining that IL-PLD can bind to CD22+NHL cells, we sought to determine if the inclusion of the HB22.7 targeting $\mathrm{mAb}$ in IL-PLD enabled more DXR uptake in NHL cells as compared to unmodified PLD. Raji cells $(\mathrm{CD} 22+)$ were treated with increasing concentrations of either IL-PLD or PLD. After $2 \mathrm{~h}$, cells were washed to remove any remaining drug, and DXR that had accumulated in the cells was extracted. Cells treated with PLD showed DXR accumulation only at the highest dose $(8 \mu \mathrm{g} / \mathrm{mL})$, while cells treated with IL-PLD exhibited increasing DXR accumulation beginning at the $1 \mu \mathrm{g} / \mathrm{mL}$ dose (Fig. 3).
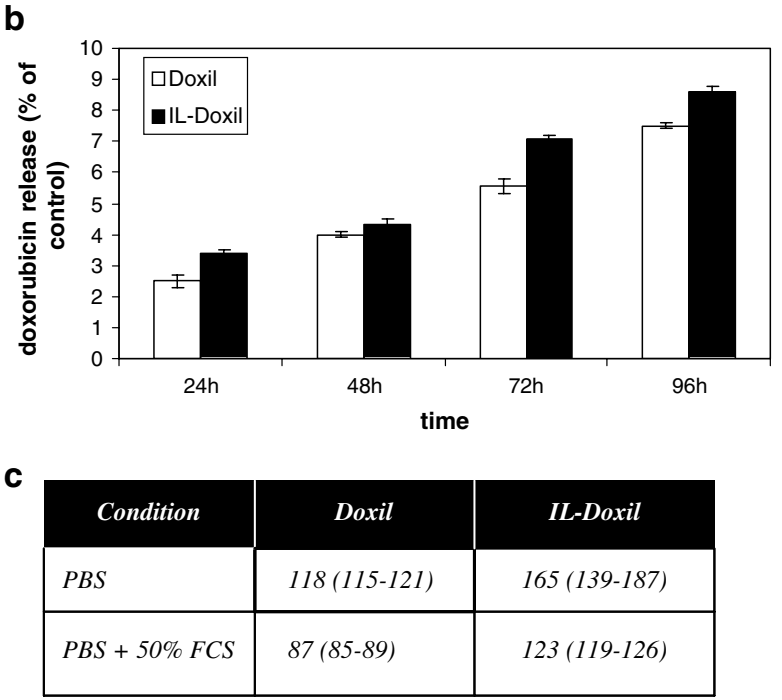

DXR released from IL-PLD and PLD dialyzed against PBS. c Mean diameter (nm) of IL-PLD and PLD measured in PBS or PBS containing $50 \% \mathrm{FCS}$. The $95 \%$ range values are given in parentheses

NHL cell lines exhibit more cytotoxicity with IL-PLD treatment compared to PLD treatment

We next compared the cytotoxic effects of IL-PLD to PLD and NL-DXR. Raji (CD22+) or Jurkat (CD22-) cells were incubated for $72 \mathrm{~h}$ with increasing doses of IL-PLD, PLD, or NL-DXR and cytotoxicity assessed by trypan blue exclusion assay (Fig. 4). IL-PLD exhibited more cytotoxicity than PLD in the CD22+ cell line (Fig. 4a, c). There was no difference between IL-PLD and PLD treatments in the CD22- cell line (Fig. 4b, d). At lower concentrations, both IL-PLD and PLD were less cytotoxic than NL-DXR in both CD22+ and CD22cells (Fig. 4a, b). For CD22+ cells, the $\mathrm{IC}_{50}$ of IL-PLD was lower than that of PLD $(0.07 \mu \mathrm{g} / \mathrm{mL}$ versus $0.22 \mu \mathrm{g} / \mathrm{mL}$ for Raji and $0.16 \mu \mathrm{g} / \mathrm{mL}$ versus $0.89 \mu \mathrm{g} / \mathrm{mL}$ for Ramos (Fig. $4 \mathrm{c}$ and Table 1). For CD22- Jurkat cells, the $\mathrm{IC}_{50}$ of IL-PLD was similar to that of PLD $(0.11 \mu \mathrm{g} / \mathrm{mL}$ versus $0.10 \mu \mathrm{g} / \mathrm{mL})$ (Fig. $4 \mathrm{~d}$ and Table 1). Since continuous in vitro treatment for $72 \mathrm{~h}$ does not accurately reflect conditions that would occur in the blood circulation in vivo, we compared continuous $72 \mathrm{~h}$ in vitro treatment with $1 \mathrm{~h}$ treatment followed by several washes, replacement with fresh treatment-free media, and assessment $71 \mathrm{~h}$ later (Fig. 5 and Table 2). The cytotoxicity of IL-PLD, PLD, and NL-DXR decreases under washing conditions (Fig. $5 \mathrm{~b}$ ) versus continuous treatment (Fig. 5a). There is a 3 -fold increase in the $\mathrm{IC}_{50}$ of IL-PLD under washing conditions compared to continuous treatment, while there is an 11- and 43-fold increase in the $\mathrm{IC}_{50}$ of PLD and NL-DXR, respectively, under washing conditions compared to continuous treatment (Table 2). 
Fig. 2 IL-PLD binds to CD22+ cells but not CD22- cells. Burkitt's B-lymphoma cells (CD22+) Raji (a) and Ramos (c) or $\mathrm{T}$ cell leukemia (CD22-) Jurkat (d) were incubated with $5 \mu \mathrm{g} \mathrm{IL-PLD} / \mathrm{ml}$ for $1 \mathrm{~h}$ on ice. Panel b is a negative control (Raji cells incubated with goat anti-mouse Ig only (no IL-PLD). Cells were washed three times with cold PBS to remove the unbound IL-PLD and incubated with FITC-labeled goat anti-mouse Ig for $1 \mathrm{~h}$. Cells were again washed three times with PBS and fixed with $2 \%$ paraformaldehyde and images were acquired with a fluorescence microscope. (a), (b) and (d) are $40 \times$ and (c) is $60 \times$ magnification
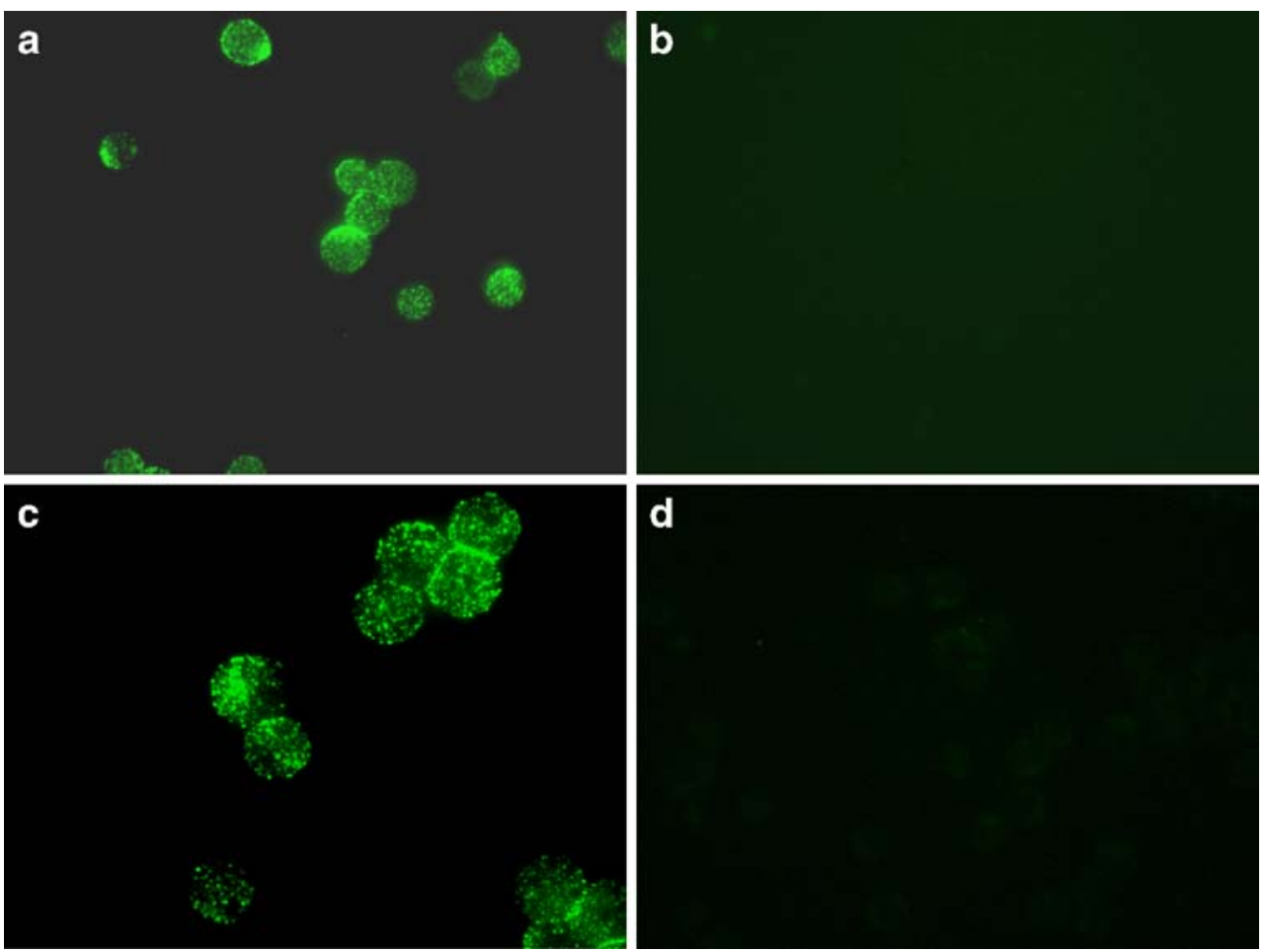

\section{Discussion}

Liposomal formulations of chemotherapy, such as PLD, can offer increased efficacy and reduced toxicity compared to their non-carrier mediated formulations, such as DXR [7]. With the inclusion of mAbs on the liposomal surface, immunoliposomes can offer even greater efficacy enhancement and toxicity reduction versus unmodified/non-targeted liposomal agents. The anti-CD22 mAb, HB22.7, has been shown to cause tumor regression in nude mice bearing Raji xenografts [16]. To combine the cytotoxicity of PLD and HB22.7 we We conjugated HB22.7 to PLD, creating a CD22 targeted immunoliposomal form of PLD (IL-PLD).

SDS-PAGE confirmed that HB22.7 was indeed incorporated into PLD (Fig. 1a, right lane). The percentage of DXR that was released from the liposome was similar for PLD and IL-PLD (Fig. 1b). This indicates that the liposome's structural stability was not altered by insertion of the HB22.7 mAb. IL-PLD's mean diameter is only slightly larger than PLD's (165 nm versus $118 \mathrm{~nm}$ ) and the mean diameter is reduced by the same percentage when size is measured in buffer containing 50\% FBS (26\% and 25\% reduction for IL-PLD and PLD, respectively) (Fig. 1c). Liposome size is an important factor as larger liposomes will have more difficulty crossing the blood vessel endothelium to enter the tumor and may be cleared faster by the reticuloendothelial system. Fenestrated tumor vessels usually contain pore sizes from 100-780 nm and liposomes with diameters of 100-200 $\mathrm{nm}$ readily extravasate into the local tumor environment [21]. Assessing liposome size in buffer containing 50\% FBS may more accurately predict what the actual size of the liposome will be as part of biological solutions, preclinical animal models, and in patients. Moreover, the IL-PLD falls well within the 100 $200 \mathrm{~nm}$ range, even without measurement in 50\% FBS.

The rationale for incorporating the anti-CD22 mAb, HB22.7, onto PLD's surface was to further enhance efficacy and decrease toxicity by targeting PLD to CD22 expressing NHLs. IL-PLD is indeed able to bind to CD22 expressing NHL cell lines (Fig. 2a, c) but does not bind to a CD22 negative cell line (Fig. 2d). The HB22.7 component

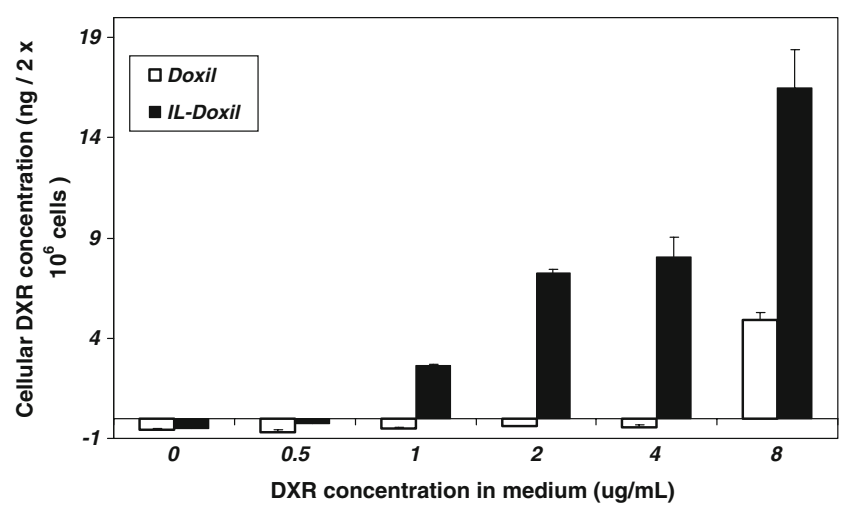

Fig. 3 DXR accumulation in NHL cell lines is greater with IL-PLD treatment than with PLD. Raji (CD22+) cells were plated in six well plates at $2 \times 10^{6}$ cells/well. The final concentrations of IL-PLD or PLD were $0,0.5 \mu \mathrm{g} / \mathrm{mL}, 1 \mu \mathrm{g} / \mathrm{mL}, 2 \mu \mathrm{g} / \mathrm{mL}, 4 \mu \mathrm{g} / \mathrm{mL}$ and $8 \mu \mathrm{g} / \mathrm{mL}$. Cells were treated for $2 \mathrm{~h}$ at $37^{\circ} \mathrm{C}$, then washed and DXR extracted with acidified isopropanol. DXR concentration was determined by microflourometer. $p$ value $\leq 0.001$ 
a

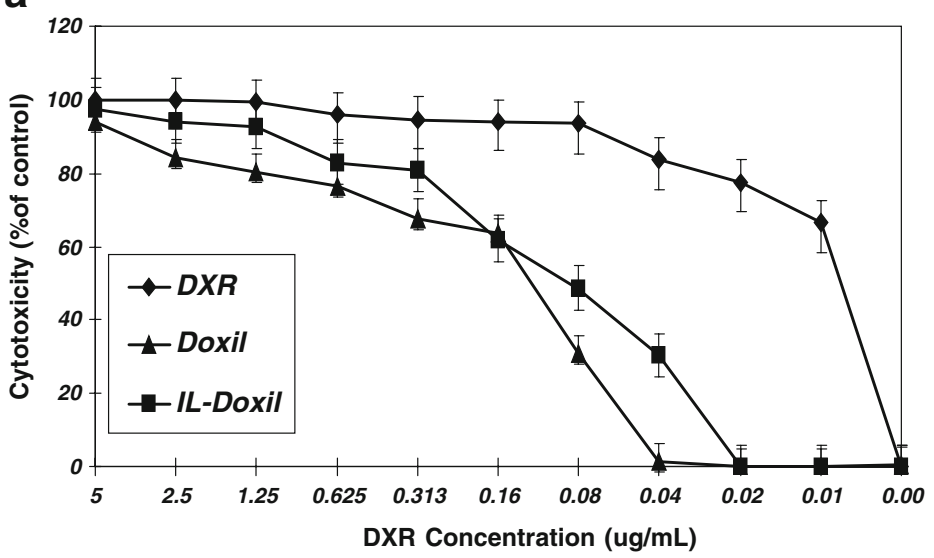

C

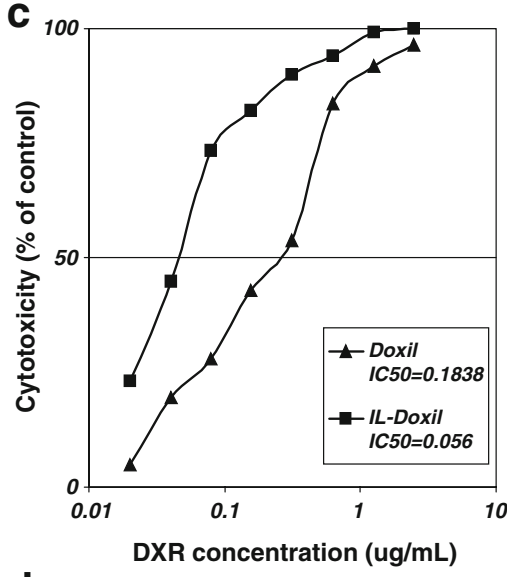

d

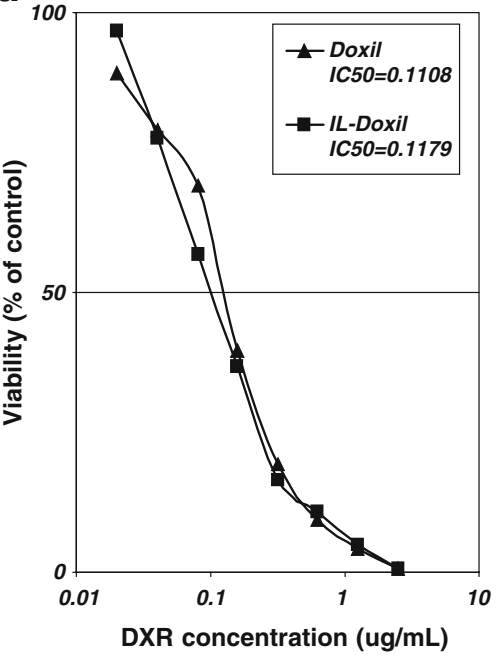

DXR concentration (ug/mL)

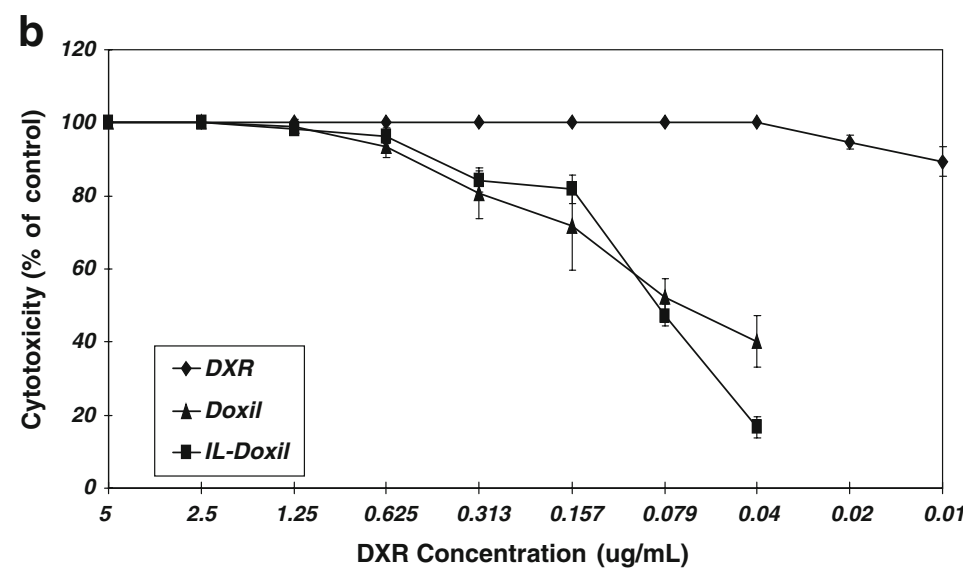

Fig. 4 IL-PLD shows increased cytotoxicity compared to PLD in CD22+ but not CD22- cell lines. CD22+Raji (a, c) or CD22- Jurkat $(\mathbf{b}, \mathbf{d})$ were treated with increasing doses of IL-PLD, PLD, or NL-
DXR and viability assessed by trypan blue exclusion. Panels $\mathbf{c}$ and $\mathbf{d}$ include $\mathrm{IC}_{50}$ calculations of IL-PLD maintains the same binding specificity as the free parent $\mathrm{mAb}$.

Other groups have created immunoliposomal forms of PLD using anti-CD19 and anti-CD20 mAbs [11, 12]. AntiCD19 immunoliposomal PLD exhibits greater efficacy than PLD in vivo, while anti-CD20 immunoliposomal PLD shows little improvement over PLD [11, 12]. CD19 is an internalizing epitope, while CD20 is a non-internalizing epitope and previous studies have shown that internalizing epitopes are needed for efficient delivery of liposomal drugs into their target cells [22]. Like CD19, our target, $\mathrm{CD} 22$, is an internalizing epitope and HB22.7 causes CD22 internalization upon binding [23]. As the HB22.7 component of IL-PLD internalizes, the liposome will be delivered into the cell. This will allow more DXR to be released into the targeted cell and enhance the cytotoxic effect compared to non-targeted PLD. CD22 is a potentially a better target than CD19 for immunoliposomal DXR therapies. A recent study shows that immunotoxins targeted to CD22 exhibit greater internalization and cytotoxicity than immunotoxins
Table 1 IC50 of cell lines continuously treated with IL-PLD, PLD, and NL- DXR for $72 \mathrm{~h}$

Data is average of three experiments for each cell line. $P$ value is for IL-PLD versus PLD groups

\begin{tabular}{llllc}
\hline & Doxorubicin & PLD & IL-PLD & $\begin{array}{l}\text { P value (PLD } \\
\text { vs IL-PLD) }\end{array}$ \\
\hline Ramos & $0.0310 \pm 0.0250$ & $0.8890 \pm 0.0276$ & $0.1640 \pm 0.0375$ & $\leq 0.001$ \\
Raji & $0.0028 \pm 0.0001$ & $0.2246 \pm 0.0746$ & $0.0717 \pm 0.0237$ & $\leq 0.005$ \\
Jurkat & $0.0055 \pm 0.0023$ & $0.0956 \pm 0.0272$ & $0.1052 \pm 0.0459$ & 0.7707 \\
\hline
\end{tabular}


Fig. 5 IL-PLD shows enhanced cytotoxicity compared to PLD when washing conditions are used to mimic in vivo circulation. Ramos cells (CD22+) were treated with increasing doses of IL-PLD, PLD, or NL-DXR for either $72 \mathrm{~h}$ continuously (a), or for $1 \mathrm{~h}$, followed by three washes and replacement with treatmentfree media, and incubated for $71 \mathrm{~h}(\mathbf{b})$, then assessed by trypan blue exclusion
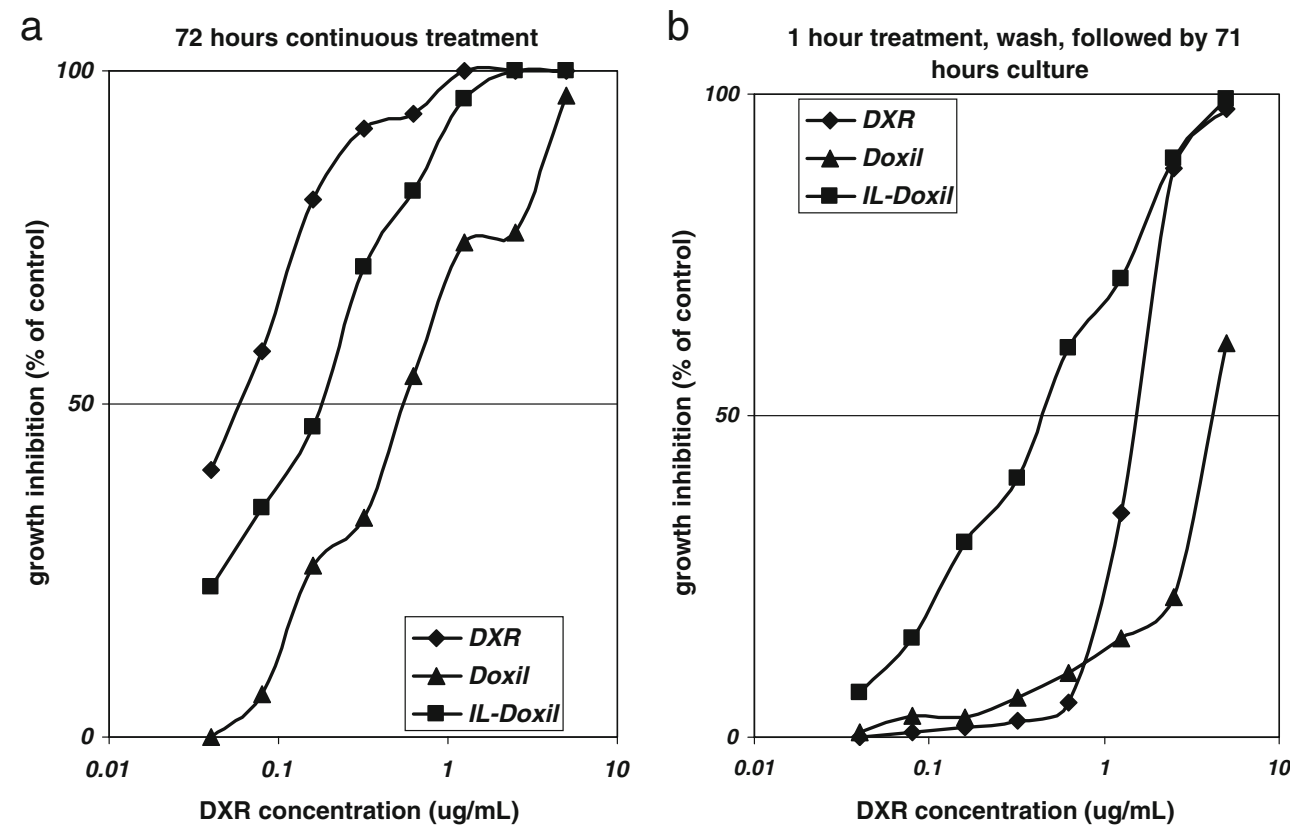

targeted to CD19, despite similar cell binding affinities between the two immunotoxins and the fact that there are fewer CD22 binding sites per cell than CD19 binding sites [24]. Figure 3 shows that DXR accumulation in CD22+ cells after $1 \mathrm{~h}$ of IL-PLD treatment occurs at $1 \mathrm{ug} / \mathrm{mL}$ and increases as the dose increases, while DXR accumulation after $1 \mathrm{~h}$ of PLD treatment only occurs at the highest dose tested $(8 \mu \mathrm{g} / \mathrm{mL})$. Increased DXR accumulation also correlates with increased cytotoxicity. Figure $4 a, 4 c$ and Table 1 demonstrate that IL-PLD shows more cytotoxicity and has a lower $\mathrm{IC}_{50}$ than PLD in CD22+ NHL cells. It is also important to note that IL-PLD's increase in cytotoxicity is specific for CD22+ cells, as a CD22- cell line showed no difference in cytotoxicity or IC50 between IL-PLD and PLD (Fig. 4b, d, and Table 1).

Though IL-PLD is more cytotoxic than PLD in CD22+ cells, both IL-PLD and PLD are less cytotoxic than NL-DXR in both CD22+ and CD22- cells (Fig. 4a, c, and Table 1). NL-DXR is a highly cytotoxic and non-specific (untargeted) drug with a large volume of distribution [25], which explains DXR's adverse effects such as cardiomyopathy [4] and myelosuppression [5, 6]. If NHL cells are treated for a short period of time, then washed, the cytotoxic effects of NL-DXR should decrease to a greater extent than that of PLD or IL-PLD. Due to the HB22.7's ability to keep IL-PLD bound to the cell, IL-PLD's cytotoxic effects should be the least affected by washing. To test this, we compared treating cells with NL-DXR, PLD, or IL-PLD continuously for $72 \mathrm{~h}$, and treating cells for only $1 \mathrm{~h}$ followed by several washes and re-plating of the cells in fresh, treatment-free medium for $71 \mathrm{~h}$. Figure 5 and Table 2 demonstrate that the cytotoxicities of all three treatments in CD22+Ramos cells decrease under washing conditions versus continuous treatment. However, the magnitude of the decreases in cytotoxicity vary dramatically depending on the treatment (Table 2). NLDXR under washing conditions exhibits a large 43.8-fold increase in $\mathrm{IC}_{50}$ over continuous treatment $(1.35 \mu \mathrm{g}$ versus $0.03 \mu \mathrm{g} / \mathrm{mL}$ ), PLD under washing conditions exhibits an 11.2-fold increase in $\mathrm{IC}_{50}$ over continuous treatment (9.96 $\mu \mathrm{g} / \mathrm{mL}$ versus $0.88 \mu \mathrm{g} / \mathrm{mL}$ ), and IL-PLD under washing conditions exhibits a 3.01 -fold increase in $\mathrm{IC}_{50}$ over continuous treatment $(0.50 \mu \mathrm{g} / \mathrm{mL}$ versus $0.16 \mu \mathrm{g} / \mathrm{mL})$ (Table 2, B/A ratio). This demonstrates that IL-PLD remains bound to the NHL cells and continues to exert cytotoxic effects, while PLD and especially NL-DXR are more easily separated from the cells, sparing the cells from their cytotoxic effects. This has important in vivo implications as the blood circulation will act to "wash" chemotherapy away from their intended targets. The inclusion of HB22.7 on ILPLD will better resist such clearing away by the circulation

Table 2 IL-PLD growth inhibitory effects on CD22+ cell line are enhanced compared to PLD under washing conditions

\begin{tabular}{llll}
\hline & $\begin{array}{l}\text { A. IC50 } \\
\text { Continuous } \\
\text { treatment }\end{array}$ & $\begin{array}{l}\text { B. IC50 Wash } \\
\text { after 1 h of } \\
\text { treatment }\end{array}$ & B/A \\
\hline Doxorubincin & 0.031 & 1.359 & 43.8 \\
PLD & 0.889 & 9.967 & 11.2 \\
IL-PLD & 0.164 & 0.505 & 3.01 \\
\hline
\end{tabular}

The IC50 values for Fig. 6 are shown along with a ratio of the IC50 under washing conditions : IC50 under continuous treatment conditions $(\mathrm{B} / \mathrm{A})$ 
and thus IL-PLD should show more in vivo efficacy in NHL tumors than PLD or NL-DXR. Furthermore, the specificity of HB22.7 for CD22 should allow IL-PLD to be less toxic compared with NL-DXR, as only the CD22 expressing NHL tumor will be targeted, sparing other healthy tissues.

Acknowledgements This work was supported in part by Veterans Administration Merit Award, Leukemia and Lymphoma Society Translational Research Award, UC Davis Health Sciences Grant, the Schwedler Family Foundation, and the deLeuze Endowment for the Non-toxic Cure of Lymphoma.

Open Access This article is distributed under the terms of the Creative Commons Attribution Noncommercial License which permits any noncommercial use, distribution, and reproduction in any medium, provided the original author(s) and source are credited.

\section{References}

1. Schumer ST, Joyce RM (2003) Radioimmunotherapy for NonHodgkin's Lymphoma. Progress in Oncology 46-72

2. Ries L, Melbert D, Krapcho M, Stinchcomb D, Howlader N, Horner M, Mariotto A, Miller B, Feuer E, Altekruse S, Lewis D, Clegg L, Eisner M, Reichman M, Edwards BE (2008) SEER cancer statistics review, 1975-2005. National Cancer Institute, Bethesda, MD

3. Hortobagyi GN (1997) Anthracyclines in the treatment of cancer. An overview. Drugs 54(Suppl 4):1-7. doi:10.2165/00003495199754010-00001

4. Legha SS, Benjamin RS, Mackay B, Ewer M, Wallace S, Valdivieso M, Rasmussen SL, Blumenschein GR, Freireich EJ (1982) Reduction of doxorubicin cardiotoxicity by prolonged continuous intravenous infusion. Ann Intern Med 96:133-139

5. Gralla EJ, Fleischman RW, Luthra YK, Stadnicki SW (1979) The dosing schedule dependent toxicities of adriamycin in beagle dogs and rhesus monkeys. Toxicology 13:263-273

6. Henderson BM, Dougherty WJ, James VC, Tilley LP, Noble JF (1982) Safety assessment of a new anticancer compound, mitoxantrone, in beagle dogs: comparison with doxorubicin. I. Clinical observations. Cancer Treat Rep 66:1139-1143

7. Northfelt DW, Martin FJ, Working P, Volberding PA, Russell J, Newman M, Amantea MA, Kaplan LD (1996) Doxorubicin encapsulated in liposomes containing surface-bound polyethylene glycol: pharmacokinetics, tumor localization, and safety in patients with AIDS-related Kaposi's sarcoma. J Clin Pharmacol 36:55-63

8. Maeda H, Sawa T, Konno T (2001) Mechanism of tumor-targeted delivery of macromolecular drugs, including the EPR effect in solid tumor and clinical overview of the prototype polymeric drug SMANCS. J Control Release 74:47-61. doi:10.1016/S0168-3659 (01) 00309-1

9. Gabizon A, Martin F (1997) Polyethylene glycol-coated (pegylated) liposomal doxorubicin. Rationale for use in solid tumours. Drugs 54 (Suppl 4):15-21

10. Symon Z, Peyser A, Tzemach D, Lyass O, Sucher E, Shezen E, Gabizon A (1999) Selective delivery of doxorubicin to patients with breast carcinoma metastases by stealth liposomes. Cancer
86:72-78. doi:10.1002/(SICI) 1097-0142(19990701) 86:1<72:: AID-CNCR12>3.0.CO;2-1

11. Allen TM, Mumbengegwi DR, Charrois GJ (2005) Anti-CD19targeted liposomal doxorubicin improves the therapeutic efficacy in murine B-cell lymphoma and ameliorates the toxicity of liposomes with varying drug release rates. Clin Cancer Res 11:3567-3573. doi:10.1158/1078-0432.CCR-04-2517

12. Sapra P, Allen TM (2004) Improved outcome when B-cell lymphoma is treated with combinations of immunoliposomal anticancer drugs targeted to both the CD19 and CD20 epitopes. Clin Cancer Res 10:2530-2537. doi:10.1158/1078-0432.CCR-03-0376

13. Tedder TF, Tuscano J, Sato S, Kehrl JH (1997) CD22, a B lymphocyte-specific adhesion molecule that regulates antigen receptor signaling. Annu Rev Immunol 15:481-504. doi:10.1146/annurev. immunol.15.1.481

14. Sato S, Tuscano JM, Inaoki M, Tedder TF (1998) CD22 negatively and positively regulates signal transduction through the B lymphocyte antigen receptor. Semin Immunol 10:287-297. doi:10.1006/smim.1998.0121

15. Tuscano JM, Riva A, Toscano SN, Tedder TF, Kehrl JH (1999) CD22 cross-linking generates B-cell antigen receptor-independent signals that activate the JNK/SAPK signaling cascade. Blood 94:1382-1392

16. Tuscano JM, O'Donnell RT, Miers LA, Kroger LA, Kukis DL, Lamborn KR, Tedder TF, DeNardo GL (2003) Anti-CD22 ligandblocking antibody HB22.7 has independent lymphomacidal properties and augments the efficacy of 90Y-DOTA-peptide-Lym-1 in lymphoma xenografts. Blood 101:3641-3647. doi:10.1182/blood2002-08-2629

17. Tuscano J, Engel P, Tedder TF, Kehrl JH (1996) Engagement of the adhesion receptor $\mathrm{CD} 22$ triggers a potent stimulatory signal for B cells and blocking CD22/CD22L interactions impairs T-cell proliferation. Blood 87:4723-4730

18. Sakakibara T, Chen FA, Kida H, Kunieda K, Cuenca RE, Martin FJ, Bankert RB (1996) Doxorubicin encapsulated in sterically stabilized liposomes is superior to free drug or drug-containing conventional liposomes at suppressing growth and metastases of human lung tumor xenografts. Cancer Res 56:3743-3746

19. Ishida T, Iden DL, Allen TM (1999) A combinatorial approach to producing sterically stabilized (Stealth) immunoliposomal drugs. FEBS Lett 460:129-133. doi:10.1016/S0014-5793(99) 01320-4

20. Fiske C, Subbarow Y (1925) The colorimetric determination of phosphorus. J Biol Chem 66:375-400

21. Abraham SA, Waterhouse DN, Mayer LD, Cullis PR, Madden TD, Bally MB (2005) The liposomal formulation of doxorubicin. Methods Enzymol 391:71-97. doi:10.1016/S0076-6879(05) 91004-5

22. Sapra P, Allen TM (2002) Internalizing antibodies are necessary for improved therapeutic efficacy of antibody-targeted liposomal drugs. Cancer Res 62:7190-7194

23. Haas KM, Sen S, Sanford IG, Miller AS, Poe JC, Tedder TF (2006) CD22 ligand binding regulates normal and malignant B lymphocyte survival in vivo. J Immunol 177:3063-3073

24. Du X, Beers R, Fitzgerald DJ, Pastan I (2008) Differential cellular internalization of anti-CD19 and -CD22 immunotoxins results in different cytotoxic activity. Cancer Res 68:6300-6305. doi:10.1158/ 0008-5472.CAN-08-0461

25. Soloman R, Gabizon AA (2008) Clinical pharmacology of liposomal anthracyclines: focus on pegylated liposomal Doxorubicin. Clin Lymphoma Myeloma 8:21-32. doi:10.3816/ CLM.2008.n.001 